\title{
Towards Adult Information Literacy Assessment in Latvia: UNESCO Media and Information Literacy Competency Matrix in Practice
}

\author{
Baiba Holma, Liga Krumina, Daina Pakalna, and Jelena Avanesova \\ University of Latvia, Faculty of Social Sciences, Lomonosova Str. 1a, LV-1019 Riga, Latvia \\ \{Baiba. Holma, Liga. Krumina, Daina. Pakalna, Jelena. Avanesova\} @lu. Iv
}

\begin{abstract}
The study presents conclusions regarding the possibility of adapting the UNESCO MIL Competency Matrix and developing methodology for information literacy assessment of the adult population. During field research in a sample territory (Kekava district) and within an adult population target group, the levels of information literacy are assessed, and information literacy education needs are clarified. The research results can be used for the development of diagnostic instruments for regional growth, planning of adult education, elaboration of information literacy training programmes, as well as for self-evaluation of information literacy competencies. The study has been carried out within the framework of the European Social Fund project "Development of Innovative Diagnostic Instruments for Regional Growth".
\end{abstract}

Keywords: UNESCO MIL Competency Matrix, livelihood, information literacy, measurement and assessment, performance criteria, Latvia.

\section{Introduction}

This study is conducted to develop diagnostic instruments for the assessment of information literacy knowledge and skills of the adult population between the ages of 25 and 62. It is characteristic of this target group to be active socially and economically, and to have the need to adapt themselves to the changes caused by technology in an information society. Information is a substantial daily resource for these people, and its aim is to satisfy their need to obtain or to supplement their knowledge. Information can be deemed as one of the livelihood resources.

The theoretical approach of this study is the 'livelihood' concept, broadened by social and cultural dimensions. The concept 'livelihood' defines resources that can be used or shared to satisfy the needs of an individual, family or other social group. "This may involve information, cultural knowledge, social networks and legal rights, as well as tools, land or other physical resources" [1, p. 12]. An "economically active population' is a social group, that obtains and processes information to increase or change their qualifications based on the labour market, and/or to satisfy their daily interests. The ability to find various sources of information, to evaluate quality and relevancy, to create new information and communicate it to others, is essential to this 
population group "in all aspects of their life, including work and lifelong learning, in relation to their personal well-being, and in their participation in civil society" [2]. The aforenamed knowledge and skills form information literacy.

'Information literacy' is one of the central concepts of this study. Since 1974 when Paul G. Zurkowski first presented a definition of this concept [3], it has raised many discussions [4]. In 2013 UNESCO defined 'information literacy' as ,a set of competencies that empowers citizens to access, retrieve, understand, evaluate and use, to create as well as share information and media content in all formats, using various tools, in a critical, ethical and effective way, in order to participate and engage in personal, professional and societal activities" [5, p. 29]. This definition corresponds with the theoretical approach in the study, and forms the basis for development of diagnostic instruments of information literacy.

The analysis of previous studies indicates that the attention of researchers was primarily focused on information literacy in formal education - training and assessment at schools or higher education institutions (e.g., [4], [6-8]). In terms of formal education it is relatively easier to develop assessment criteria to determine the level of information literacy because there are appropriate standards available (e.g., the Information Literacy Competency Standards for Higher Education [9]). When it comes to an economically active adult population, there are no such standards available; therefore it is the aim and main challenge of the study to develop a methodology for estimating information literacy levels and education needs in this population group.

The objective of the study is to analyse the implementation methodology of the UNESCO Media and Information Literacy (MIL) Competency Matrix in assessment of adult information literacy, and to characterize the information literacy education needs of the adult population in a sample territory of Latvia (Kekava district). The study was carried out within the framework of the European Social Fund project "Development of Innovative Diagnostic Instruments for Regional Growth”.

\section{UNESCO MIL Assessment Framework}

In order to examine the information literacy levels of the population and what knowledge and skills (competencies) need to be developed or improved, the study is based on the UNESCO MIL Assessment Framework "which leads to the assessment of proficiency level for grading the various information literacy competencies" [5, p. 60]. According to this Framework, the $1^{\text {st }}$ information literacy level (basic) indicates that a respondent has basic skills and knowledge, "but significant improvements are needed for effective application". The $2^{\text {nd }}$ level (intermediate) indicates that "a respondent has a good level of knowledge and skills, but there are gaps in certain areas". The $3^{\text {rd }}$ level (advanced) indicates that "a respondent has a very good level of knowledge and skills" [5, p. 60]. Additionally, in this study, a zero level is introduced, projecting that there are people who do not possess the knowledge and skills needed for the basic level. This proved to be true when assessing the results of practical tasks. The zero level indicates that an individual's information literacy is so low that it can become a serious constraint for obtaining information - a significant livelihood resource. 
There are definite indicators structured into three MIL components describing every level of information literacy. The $1^{\text {st }}$ level indicators of the MIL Component 1 (C1: Access) are as follows: a respondent can define his information needs, can choose an appropriate source to obtain information, is able to perform a search, and can temporarily save the information found. The $2^{\text {nd }}$ level indicators show that a respondent is aware that the definition of needs can vary, that there can be at least two sources of information, and that there can be different methods of search and storage of the information. The $3^{\text {rd }}$ level means that a respondent can define his information needs according to the search strategy. He is able to select the most relevant sources of information, has good knowledge and ability to select the most appropriate information search method, and can save the information as required under certain conditions. The zero level indicates that a respondent finds it difficult to define his information needs and correspondingly, to find and select the source of information and to store the data found.

The MIL Component 2 (C2: Evaluation) indicators according to levels are as follows: there are no clear evaluation criteria for selection of information sources in the $1^{\text {st }}$ level, as often the first one found or the one easier to access is selected. Organization of useful information for storage and repeated use is neither thought-out nor skillful. The $2^{\text {nd }}$ level indicators of this component show that a respondent knows the criteria for a qualitative information source and applies them in practice, and can organize information for storage and repeated use. The $3^{\text {rd }}$ level indicators show that a respondent can evaluate the relevance and quality of an information source according to various criteria, is capable of saving it skillfully, and organizing it thoughtfully. The zero level indicates that a respondent finds it hard to choose a source, having no criteria for that purpose, and often does not know how to organize information sources for storage and repeated use.

The MIL Component 3 (C3: Creation) indicators according to levels are as follows: the $1^{\text {st }}$ level means that a respondent can summarize the obtained information, can disseminate the information, pays no attention to considerations of copyright, and knows about e-services and information exchange possibilities through modern ICT. The $2^{\text {nd }}$ level indicates a respondent can create new information and new formats from the obtained information, knows that there are various types and channels for dissemination of information, and knows how to use them. He adds a short disclaimer to a fragment of information about its origin, and knows how to use e-services. The $3^{\text {rd }}$ level indicates that a respondent can analyze, evaluate critically and create new information obtained from various sources, is aware of copyrights, can choose and use the information distribution means according to a particular group of recipients, can disseminate private information on the web being aware of the risks, and uses various e-services. The zero level indicates that a respondent does not have knowledge to summarize the information or can do it poorly, has low computer literacy and information processing skills, and has a low level of copyright awareness regarding the use of information and data. 


\section{$3 \quad$ Research Methodology}

The empirical basis for the study is a micro model ( 23 people between the ages of 26 and 62) of the economically active population in the sample territory (Kekava district). This micro model reflects a proportional distribution of age, education, occupation, gender, and computer literacy. There are three data collection methods used in the study: focus group interviews, questionnaires, and practical tasks. There were two groups of people taking part in the study, and the data of each group were obtained, implementing all three methods consecutively during a single meeting. Field studies were conducted in local libraries.

Prior to the focus group discussions, each participant was asked to complete a questionnaire as to their education, occupation, age, income level and self-assessment of computer literacy. This information was used for analysis of the knowledge questionnaire data and selection of the respondents to perform practical tasks.

There were two focus group discussions organized to study the participants' daily information practice, main problems in accessing information, and education needs in this respect. The topics were arranged in three categories: 1) importance of information in the respondents' daily life (situations when information is required; sources where to find it); 2) problems that prevented finding the needed information; and 3) knowledge and skills dealing with information (a lack of specific skills and/or education needs). The discussion transcripts were coded according to the specified data sets (the software NVivo was used for data analysis).

In order to assess seeking, evaluation and use of information, respondents completed a knowledge questionnaire. The questionnaire consists of 23 questions on various daily life situations (e.g., visiting a doctor, purchasing a washing machine, finding a food recipe, preparing a greeting card), which can be done through searching for information and its use. The first eight questions (Block A: Access) were to determine knowledge in accessing information, including the ability to define a request, knowledge of various information sources and search tools, implementation of a database search, access to found sources, and knowledge of options to temporarily save information. The next seven questions (Block B: Evaluation) were posed to learn the knowledge of assessing information and information sources. In these questions respondents had to show their knowledge of various reliability criteria, that is, which criteria should be taken into account when selecting an information source (e.g., assessment of a topic, author, publisher, genre, date of publication), and organizing or saving of useful sources of information. The third group of eight questions (Block C: Creation) focused on establishing knowledge of use of the information found. There were questions about information analysis and synthesis, ethical aspects for the use of information (e.g., correct references to the information sources used), preparing information for a presentation, sharing information with other people, and about the knowledge needed for use of sensitive data.

The knowledge questionnaire consists of three types of closed-ended questions: 1) multiple choice answers where there is only one answer variant to be selected, 2) multiple choice answers where one can select several answers, 3) rating scale questions. The prevailing type of questions is multiple choice, where there is only one 
answer to be selected (65\%). It has to be noted that the main problems with questionnaire processing are multiple choice answers, where several answer variants can be selected, requiring thinking about coding in terms of different combinations of answer variants, and associating them with the respective levels of information literacy. But questions of this type are developed with the purpose of "enlivening" the questionnaire and making sure that the answers are not too predictable. A correct definition of questions enabling respondents to understand them and to be able to assess the level of information literacy of population is a challenge in development of the quesionnaire. The questions were improved several times, including after a pilot test. Questionnaire developers often discussed definitions of knowledge and skill levels. There were several reasons for differences in opinion: 1) diversity of the best possible action in obtaining and using information; 2) lack of needed information literacy standards for daily life; 3) daily information search patterns observed, which are often based on the principle of least effort, selecting the ease of access information source, and ease of use search tool, and trying to spend as little time as possible on it [10].

In order to establish the population's skills in access, evaluation and creation of information, they were required to complete some practical tasks. The think aloud method was applied in order to record the activities of participants when performing practical information searches in the Internet environment. This method records the information search process (navigation) most precisely. It includes the respondent's thoughts and motivation for 1) selecting a particular way to search, 2) selecting specific information sources, 3) questioning the credibility of the source, 4) making a final selection, and 5) summarizing the obtained information in a new form. The screenshot recording software BB Flash Back Express was used to record the sequence of doing a practical task. This enables precise and qualitative recording of screen activities, including sound, and also furnishes data analysis.

Using the principle of coincidence, each respondent was given the opportunity to select two practical tasks. These were related to daily life situations (e.g., job hunting, planning of trips or visiting cultural events, health issues, shopping. Task example: "'Spring fatigue' may be caused by lack of iron in the body. Please find in your opinion the three most reliable sources of information and give the three most common herbal products that are recommended for use. Please summarize the information found in the Word file, name it 'Health', and save it on your desktop in a folder called 'Tasks' "). The information found had to be summarized, compared and saved or sent by e-mail.

Only four participants from each group of respondents took part in doing practical tasks. They were selected based on the questionnaires (age, gender, education) completed prior to the focus group discussions. The respondents' computer literacy self-assessment was also taken into account. Every respondent had an observer who followed the process, provided reminders of the conditions of assignments, but was not allowed to interfere or help.

Think aloud results are processed and analyzed according to C1: Access, C2: Evaluation, C3: Creation. All records are transcribed and supplemented with comments on the activities on screens and screenshots. Data are coded according to the subject matter of every component. The information literacy level is assigned to every component and the overall average of all three components is calculated. 


\section{Information Practice and Information Literacy Education Needs of Adult Population}

The information practice and education needs of respondents were examined during focus group discussions. In total 23 participants, whose average age was 45, took part. Participants represented various employment groups (e.g., librarian, lawyer, chemist, teacher, historian), including some unemployed people and homemakers. Two librarians (one in each focus group) were enrolled to examine whether senior age (in the first case) or lack of professional education in librarianship (in the second case) leads to the same information literacy problems as can be observed for other residents of the district.

In order to analyze the opinions of participants, the content of discussions' transcripts was coded in six data sets: 1) subject categories of needed information, 2) information sources, 3) information communication channels, 4) problems in obtaining the information, 5) lack of specific knowledge and skills, 6) information literacy education needs.

The first data set, 'subject categories of needed information', indicates the respondents have a daily need for information in 23 subject categories (53 subjects). The categories refer to entertainment, district life, gardening, housekeeping and domestic animals, music, medicine, sports, and public transport inquiries, etc. The interests of respondents in employment or government information (e.g., submission of income declaration, annual report of a public organization, application for area payments), suggest the economic and social activity of participants. The largest number of references coded refers to district or parish life. This is also the most frequently mentioned subject category in focus groups. This information need would seem to be natural in that a participant would want to manage life in his/her place of residency (in this example, Kekava district).

When analyzing for the second data set. 'information sources', respondents (regardless of their age, education and occupation) prefer websites and Internet search engines (e.g., Google, draugiem.lv, kultura.lv). Another significant group of information sources is people (e.g., colleagues, friends, officials, neighbours, postmen, accquintances). It is followed by databases and printed sources (books and periodicals). The Internet is also the most significant communication channel in the data set 'information communication channels'. A reference to the prevailing role of the Internet lets us draw a conclusion that both computer literacy skills, and information search and evaluation skills, are important to respondents to ensure the quality and relevance of information obtained.

A vast majority of what was provided in the data set 'problems in obtaining the information' refers to the scope, volume of the information available on the web and usability of sources and software. However, there are some problems that can be eliminated through the improvement of information literacy. The most substantial problem of this group is not having a good command of a foreign language (if there is no information on the Latvian web or it is not sufficiently detailed and specific). This is followed by a lack of software usage skills (e.g., forgot how to do things, or has no understanding of the most recent software versions). This conclusion correlates with the results in the data set, 'lack of specific knowledge and skills'. Poor foreign language 
skills were also among the most often mentioned, including the inability to act on the required level with Internet search engines or computers in general.

The last data set, 'information literacy education needs' should be viewed both in the context of problems in obtaining information and a lack of knowledge and skills. Education needs refer to information search (Google options and tools, easiest and shortest ways for finding information), information evaluation (credibility check of information and establishing objectivity), information processing and analysis, presentation of information (creating diagrams or charts). Acquiring technologies was emphasized particularly (e.g., software, usage of Internet multimedia platforms, creation of blog entries). Similarly to the aforesaid, foreign languages were mentioned in this data set too (not only English, but also Russian and German).

Content analysis of the focus group discussions showed training is needed in all three components of the MIL Matrix. Particular attention should be paid to computer literacy when organizing training in any of the components.

\section{$5 \quad$ Assessment of Information Literacy Levels}

\subsection{Knowledge in Access, Evaluation and Creation of Information}

This part of the paper is dedicated to the overview of the survey results in two major cities of Kekava district: Balozi (65 respondents) and Kekava (33 respondents). The survey took place between April 24 and May 17, 2014. The paper questionnaires were distributed primarily through libraries and kindergartens in Balozi. The selection is thus biased towards the visitors of the establishments mentioned. This partly explains why $76 \%$ of respondents are females, as well as why $80 \%$ of total respondents have higher education (32\% - a Bachelor's degree plus 39\% - a Master's degree). Moreover, 5 out of 19 respondents without higher education are current students.

The division between the age groups was more even: $37 \%$ (25-34 years old); $26 \%$ (35-44 y.o.); $17 \%$ (45-54 y.o.) and 20\% (55-62 y.o.). The majority of respondents $(69 \%)$ work full time, but the earnings vary significantly. Almost one quarter of persons $(23 \%)$ receive between EUR $231-400$ as monthly net, while others (22\%) earn EUR 401-550 per month. 21\% earn more, but only 4\% receive more than EUR 1000. Approximately 4\% earn less than EUR 100 per month.

The knowledge questionnaire was split into four blocks: Access (A), Evaluation (B), and Creation (C) and background demographics (D). The answers and combination of answers from the first three blocks were then leveled to the preconstructed information literacy level scale. Four levels were defined for each question, from 0-the lowest to 3-the highest, 0-level was most often assigned for "do not know" answers.

Respondents' information literacy levels varied greatly even in one block of questions. Level 2 responses to questions in Block A applied to the majority of participants (Block A considered the choice of different information sources, e.g., finding a good therapist, or short-term storage of data, such as storing a recipe for one-time use). In a search of different kinds/formats of information (e.g., searching for a video from a specific popular event, or a book from any of the libraries) levels 2 or 3 were achieved. $91 \%$ achieved level 3 for the question regarding Internet search 
tools; but $67 \%$ achieved only level 1 on the optimal method for looking for a specific book (with no limitation to the source or format). On 5 out of 8 Block A questions, $10 \%$ or fewer achieved level 1; although on 2 of these 8 questions from Block A more than $50 \%$ (56\% in the first case, and $91 \%$ in the second case) achieved level 3. Thus, the average level of the respondents for $\mathrm{C} 1$ : Access is level 2.

Of the Block B questions, one was about the criteria people apply to evaluating information source reliability and accuracy. Six criteria were proposed and leveled separately based on the respondents' frequency of attention to each (author, date, publisher, design/formatting, topic relevancy, annotation/summary/reviews). More than $55 \%$ of respondents pay attention to author and topic, and least often to formatting. Close to $70 \%$ of respondents know how to assess data reliability and more trustworthy sources, as answers to 3 Block B questions proved. Moreover, $74 \%$ of respondents use some logical systematization when saving information for the longterm, and $51 \%$ are aware of the newest Cloud storing technologies. Only one question was problematic in this section, slightly spoiling the evident level 3 for the $\mathrm{C} 2$ : Evaluation. This was a more specific question asking about choosing the best source of a modern definition for the word "democracy": $49 \%$ of respondents achieved level 2 and only $38 \%$ level 3.

The questions from Block $\mathrm{C}$ were least homogenous. The first one, ethical uses of images online, resulted in $35 \%$ receiving a level 0 , with an additional $14 \%$ selfselecting "do not know the correct answer". Only 23\% got level 3 for this question. The situation improved with the next 3 questions, which showed $65 \%$ of respondents know how to process written information from different sources; $59 \%$ make correct conclusions based on the data found, and $60 \%$ effectively sort different sources of information according to reliability. $46 \%$ of respondents are more knowledgeable about sensitive data processing and specifically how to help another person work with Internet banking with no risk to either party; but only $28 \%$ fully understand how to share data, such as photos, in the most private way.

The results show C3: Creation is the most challenging MIL Component in terms of overall skills and knowledge required. Although respondents got level 2 and even 3 for some of the questions, the lack of understanding about the correct way of doing things is obvious.

This survey could be developed into a self-assessment information literacy tool. It would be improved using the results of more in-depth research provided by different methods (e.g., think aloud observed further), and further detailed comparisons of the respondents who took part in all the assessments - focus group, survey, and practical tasks.

\subsection{Skills in Access, Evaluation and Creation of Information}

Processing of practical tasks is analyzed and assessed in this part of the paper. The data gathered through the think aloud method indicates the highest results were obtained for the C1: Access (average information literacy level-2, $\bmod -3$ ). A vast majority of respondents used Google to search for information. There were no problems in terms of selecting keywords, since wording from the assignment texts was often used as keywords. 
It was slightly more difficult to deal with the C2: Evaluation (average information literacy level $-1, \bmod -2.5$ ). Many respondents selected and viewed only the first or first three search results found from the list of information sources presented.

Most difficult was the C3: Creation (average information literacy level - 1, mod 2). All assignments requested respondents to summarize and compare information from different sources. Most frequently, participants simply copied the information, neither creating their own text nor referencing the copied one. This is a stage when the problems of computer literacy (e.g., ability to copy texts, save files, create a new folder) were most evident. Two respondents experienced problems with using e-mail when dealing with the assignment. Additionally, in some cases e-mail sending etiquette was not observed, lacking text in the message body or signature.

Comparing the results by age groups, the older respondents received the highest assessments. Although they took longer to complete assignments, they assessed the information found more thoroughly and summarized it more skillfully.

The think aloud method clearly showed the online problems experienced when seeking daily life information. Although $75.5 \%$ of respondents had self evaluated their ability to find needed information online as high, the results of practical tasks showed many shortcomings. This applied to searching for information, its evaluation, and especially further processing - summarization, creation, saving, and sending. In focus group discussions, respondents self-acknowledge their deficiencies (e.g., comparison and evaluation of information sources, usage of an e-mail or software, comparison of prices). However, the think aloud method helped to determine additional problems, such as, defining the need for information, summarization, and storage of information.

\section{Conclusions}

1. The division of competence indicators into four (0-3) levels within three MIL components used in the study provides several benefits: a) it enables more objective assessment of information literacy, b) it allows more specific identification of poor/lacking knowledge and skills that have to be acquired or improved in order to achieve the highest level.

2. Survey analysis showed a questionnaire might be a good self-assessment tool for information literacy if the leveling of questions is constructed carefully and updated according to the evolving IT environment.

3. Although in terms of data collection and processing, practical tasks on searching information on the Internet and use of think aloud are time consuming, they provide credible and accurate results about people's information literacy. This method provides a deeper view into the habits of respondents and gives an opportunity to develop a much more precise information literacy self-assessment tool. This method helps determine lack of knowledge and education needs.

4. Application of various methods in the study ensures unbiased results because it compares the opinions expressed in focus groups with questionnaires and the results of practical tasks. Moreover, the education needs established during the target group discussions supplement those recognised through practical tasks. 


\section{References}

1. Wisner, B., Blaikie, P., Cannon, T., Davis, I.: At Risk: Natural Hazards, People's Vulnerability, and Disasters, 2nd edn. Routledge, New York (2004)

2. Catts, R.: Indicators of Adult Information Literacy. J. of Information Literacy 6(2), 4-18 (2012)

3. Zurkowski, P.G.: The Information Service Environment: Relationships and Priorities: Related paper No 5. National Commission on Libraries and Information Science, Washington DC (1974),

http://files.eric.ed.gov/fulltext/ED100391.pdf

4. Owusu-Ansah, E.K.: Debating Definitions of Information Literacy: Enough is Enough! Library Review 54(6), 366-374 (2005), doi:10.1108/00242530510605494

5. UNESCO Global Media and Information Literacy Assessment Framework: Country Readiness and Competencies (2013),

http: / /www . unesco.org/new/en/communication-and-information/

resources/publications-and-communication-materials/

publications / full-1ist/global-media-and-information-

literacy-assessment-framework

6. Leichner, N., Peter, J., Mayer, A.K., Krampen, G.: Assessing Information Literacy among German Psychology Students. Reference Services Review 41(4), 660-674 (2013), doi:10.1108/RSR-11-2012-0076

7. Oakleaf, M.: The Information Literacy Instruction Assessment Cycle: A Guide for Increasing Student Learning and Improving Librarian Instructional Skills. J. of Documentation 65(4), 539-560 (2009), doi:10.1108/00220410910970249

8. Whitlock, B., Nanavati, J.: A Systematic Approach to Performative and Authentic Assessment. Reference Services Review 41(1), 32-48 (2013), doi:10.1108/00907321311300866

9. Information Literacy Competency Standards for Higher Education (2000),

http: //www.ala.org/acrl/standards/informationliteracycompetency

10. Bates, M.: Information Behaviour. In: Bates, M.J., Niles Maack, M. (eds.) Encyclopedia of Library and Information Sciences, 3rd edn., vol. 3, pp. 2381-2391. CRC Press, New York (2010),

http://pages.gseis.ucla.edu/faculty/bates/articles /

information-behavior.html 